\title{
Circulating Regulatory T-Cells in Monoclonal Gammopathies of Uncertain Significance and Multiple Myeloma: In Search of a Role
}

\author{
Giovanni D'Arena, ${ }^{1}$ Giovanni Rossi, ${ }^{2}$ Luca Laurenti, ${ }^{3}$ Teodora Statuto, ${ }^{4}$ Fiorella D'Auria, ${ }^{4}$ \\ Luciana Valvano, ${ }^{4}$ Vittorio Simeon, ${ }^{5}$ Aldo Giudice, ${ }^{6}$ Idanna Innocenti, ${ }^{3}$ Vincenzo De Feo, ${ }^{7}$ \\ Rosanna Filosa, ${ }^{8}$ and Pellegrino Musto ${ }^{9}$ \\ ${ }^{1}$ Hematology and Stem Cell Transplantation Unit, IRCCS Cancer Referral Center of Basilicata, 85028 Rionero in Vulture, Italy \\ ${ }^{2}$ Hematology Unit, IRCCS “Casa Sollievo della Sofferenza” Hospital, 71013 San Giovanni Rotondo, Italy \\ ${ }^{3}$ Hematology Chair, Catholic University of "Sacred Heart", 00168 Rome, Italy \\ ${ }^{4}$ Laboratory of Clinical Research and Advanced Diagnostics, IRCCS Cancer Referral Center of Basilicata, \\ 85028 Rionero in Vulture, Italy \\ ${ }^{5}$ Laboratory of Preclinical and Translational Research, IRCCS Cancer Referral Center of Basilicata, \\ 85028 Rionero in Vulture, Italy \\ ${ }^{6}$ Epidemiology Unit, National Cancer Institute of Naples “G. Pascale Foundation”, IRCCS, 80131 Naples, Italy \\ ${ }^{7}$ Pharmacology Department, University of Salerno, 84084 Salerno, Italy \\ ${ }^{8}$ Department of Experimental Medicine, Second University of Naples, 80138 Naples, Italy \\ ${ }^{9}$ Scientific Direction, IRCCS Cancer Referral Center of Basilicata, 85028 Rionero in Vulture, Italy
}

Correspondence should be addressed to Giovanni D’Arena; giovannidarena@libero.it

Received 8 March 2016; Revised 1 May 2016; Accepted 10 May 2016

Academic Editor: Sylvain Perrucche

Copyright (C) 2016 Giovanni D’Arena et al. This is an open access article distributed under the Creative Commons Attribution License, which permits unrestricted use, distribution, and reproduction in any medium, provided the original work is properly cited.

The frequency and function of regulatory T-cells (Tregs) in multiple myeloma (MM) are still matter of debate. The percentage and absolute number of circulating Tregs $\left(\mathrm{CD} 4^{+} \mathrm{CD} 25^{\text {thigh density }} \mathrm{CD} 127^{-/ \text {low density }}\right)$ from 39 patients with untreated $\mathrm{MM}$ and 44 patients with monoclonal gammopathies of uncertain significance (MGUS) were tested and compared with 20 healthy subjects as controls. The mean percentage number of circulating Tregs was $2.1 \% \pm 1.0$ (range $0.75-6.1 \%$ ) in MM patients; $2.1 \% \pm 0.9$ (range $0.3-4.4 \%$ ) in MGUS; and $1.5 \% \pm 0.4$ (range $0.9-2.1 \%$ ) in controls $(p$ ns). Mean absolute number of Tregs was $36.3 / \mu \mathrm{L} \pm 23.7$ (range

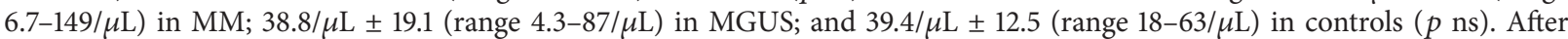
a median follow-up of 38 months, 5 MGUS and 2 smoldering MM (SMM) transformed into overt MM; however Tregs number did not predict this evolution. With respect to MM patients and after a median follow-up of 33 months, Tregs did not show any significant correlation with main clinical and laboratory characteristics. Finally, from a functional point of view, Tregs displayed an effective suppressor function, irrespective of disease status. This study indicates that the number of circulating Tregs does not differ in different monoclonal gammopathies and normal subjects and do not correlate with clinical features of MM.

\section{Introduction}

Natural and inducible regulatory T-cells (Tregs) are a small subset of T-lymphocytes able to suppress immune responses by direct interaction with other immune cell types or through immunosuppressive cytokines [1]. They appear to be crucial in maintaining immune homeostasis, mediating peripheral tolerance and preventing autoimmunity. Emerging evidences 
TABLE 1: Main patients' characteristics at study entry.

\begin{tabular}{|c|c|c|}
\hline & MM (39 patients) & MGUS (44 patients) \\
\hline \multicolumn{3}{|l|}{ Age (years) } \\
\hline (median; range) & $69(37-90)$ & $65(39-87)$ \\
\hline \multicolumn{3}{|l|}{ Gender (number; \%) } \\
\hline Male & $18(46 \%)$ & $25(57 \%)$ \\
\hline Female & $21(54 \%)$ & $19(43 \%)$ \\
\hline \multicolumn{3}{|c|}{ International staging system (ISS) (number; \%) } \\
\hline ISS-1 & $9(23 \%)$ & \\
\hline ISS-2 & $19(49 \%)$ & \\
\hline ISS-3 & $11(28 \%)$ & \\
\hline \multicolumn{3}{|c|}{ MM/MGUS subtype (number; \%) } \\
\hline $\operatorname{IgG}$ & $28(72 \%)$ & $32(73 \%)$ \\
\hline $\operatorname{Ig} \mathrm{A}$ & $11(28 \%)$ & $8(18 \%)$ \\
\hline $\operatorname{IgM}$ & - & $4(9 \%)$ \\
\hline \multicolumn{3}{|c|}{ Serum M-protein (g/dL) } \\
\hline (median; range) & $2.9(2.1-5.3)$ & $1.1(0.2-1.9)$ \\
\hline \multicolumn{3}{|c|}{ Percentage of BM plasma cells } \\
\hline (median; range) & $36(23-85)$ & $7(1-10)$ \\
\hline
\end{tabular}

BM: bone marrow; MM: multiple myeloma; MGUS: monoclonal gammopathies of uncertain significance.

suggest that Tregs may also modulate host T-cell activity against tumor-associated antigens, thereby facilitating tumor escape from immunological control [2].

Tregs are characterized by the constitutive expression of surface CD4 antigen, high levels of surface CD25 antigen (IL-2 receptor $\alpha$-chain), and the transcription factor forkhead box P3 (FOXP3), with low to nil CD127 (IL-7 receptor) [3].

We have recently demonstrated that Tregs may have a prognostic role in patients with Rai stage 0 chronic lymphocytic leukemia [4]. However, frequency and function of Tregs in monoclonal gammopathies of uncertain significance (MGUS) and multiple myeloma (MM) are still matter of debate. Aiming to evaluate a possible prognostic significance in MGUS and MM, we studied the percentage and absolute number of circulating Tregs in a consecutive, prospective cohort of these patients and in a group of healthy subjects, as controls.

\section{Materials and Methods}

Methylenediaminetetraacetic acid- (EDTA-) anticoagulated peripheral blood samples from 39 patients with newly diagnosed MM (mean age 69 years; range $37-90$ years; 18 male; 21 female) and 44 patients with MGUS (mean age 65 years; range 39-87 years; 25 male; 19 female) were collected after informed written consent. Ten out of $39 \mathrm{MM}$ patients were reclassified as having smoldering MM (SMM) just after the diagnosis. No relapsed, treated, or in remission phase after therapy patients were evaluated. Peripheral blood samples from 20 healthy subjects (mean age 59 years; range $32-80$ years; 10 male; 10 female) were used as controls. Main patients' characteristics are summarized in Table 1.

Tregs were numbered by means of flow cytometry (FACSCanto II, Becton Dickinson Biosciences (BDB), San Jose,
CA, USA) as follows: $100 \mu \mathrm{L}$ of each of the following directly conjugated monoclonal antibodies (MoAbs): CD4PerCP (peridinin chlorophyll protein complex)/CD127-PE (phycoerythrin)/CD25-Pe-Cy7 (PE-Cyanine 7)/CD45-APC$\mathrm{Cy} /($ allophycocyanin-Cy7). All MoAbs were purchased from BDB. After lysis of red blood cells and repeated washing, the samples were analyzed by flow cytometry, by acquiring a minimum of 20,000 events for each sample. All subsequent analyses were performed using FACS-Diva software (BDB). Tregs were evaluated according to the gating strategy protocol previously described (Figure 1) [12] and defined by the expression of CD4 and CD25 at high density and CD127 at low density or undetectable levels. This gating strategy was chosen because it better discriminates between Tregs and activated T-cells that normally upregulate CD25 antigen [3].

An in vitro proliferation inhibition assay, as previously described by Castella et al. [13], was used in 14 representative subjects (3 healthy controls and 4 MGUS, 3 SMM, and 4 active MM patients) to assess the suppressive function of circulating Tregs. Briefly, cell proliferation was evaluated measuring the uptake of $1 \mu \mathrm{Ci}{ }^{3} \mathrm{HTdR}$, with a scintillation counter, by cell culture in which allogeneic PBMC were used as accessory cells, purified $\mathrm{CD} 4^{+} \mathrm{CD} 25^{+} \mathrm{CD} 127^{\text {low }}$ cells as Tregs, autologous $\mathrm{CD} 4^{+} \mathrm{CD} 25^{-}$cells as responder cells, and soluble anti-CD3 as polyclonal activator. Conventional $\mathrm{CD} 4^{+} \mathrm{CD} 25^{-}$T-cells (T-conv): Treg ratio was $1: 1$. The percentage of inhibition was calculated as follows: $1-[$ (average cpm counts in $\mathrm{T}$ responders + Tregs wells) $] /[$ (average cpm counts in $\mathrm{T}$ responders wells) $] \times 100$.

2.1. Statistical Analysis. Continuous variables are reported as means, standard deviations, and range. Comparisons were performed by use of single $t$-test or ANOVA depending on the number of group compared. The degree of association 
$(\times 1,000)$
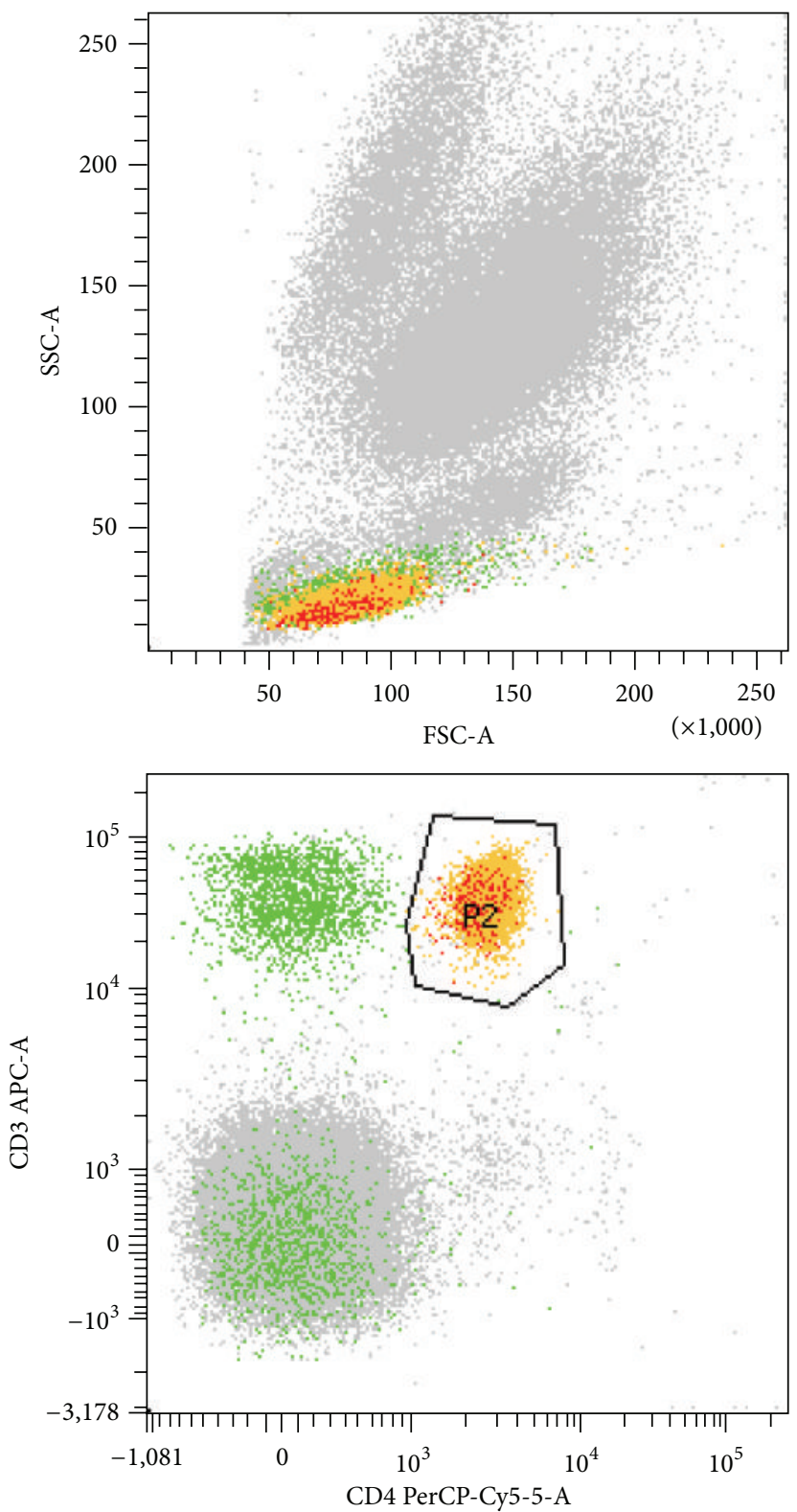

$(\times 1,000)$
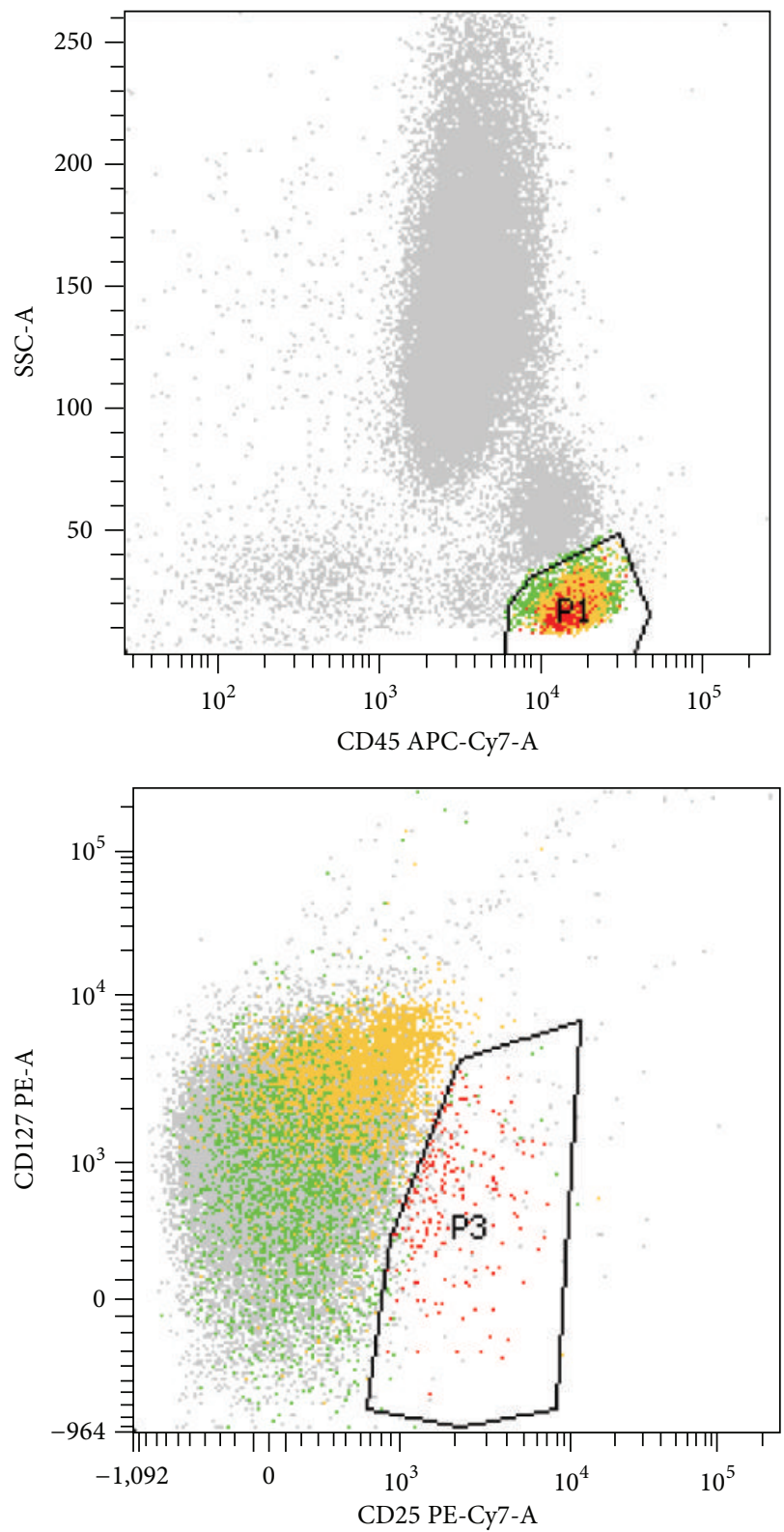

\begin{tabular}{|c|c|c|c|c|c|c|}
\hline \multicolumn{7}{|c|}{$\begin{array}{l}\text { Experiment name: CONTR 27-02-14 } \\
\text { Specimen name: CONTROLLOfV IMMUNO } \\
\text { Tube name: Tube_010 } \\
\text { Record date: Feb 27, 2014, 2:35:43 p.m. } \\
\text { \$OP: administrator } \\
\text { GUID: 0371f915-aff0-404e-a331-a665cfab257f }\end{array}$} \\
\hline Population & \#Events & $\%$ parent & $\%$ grandpar... & $\%$ total & $\begin{array}{l}\text { SSC-A } \\
\text { Mean }\end{array}$ & $\begin{array}{c}\text { CD3 APC-A } \\
\text { Mean }\end{array}$ \\
\hline$\square$ All events & 100,000 & \#\#\#\# & \#\#\#\# & 100.000 & 116,966 & 4,407 \\
\hline$\square$ P1 & 13,119 & 13.1 & \#\#\#\# & 13.119 & 18,540 & 30,360 \\
\hline$\square$ P2 & 6,756 & 51.5 & 6.8 & 6.756 & 17,444 & 36,379 \\
\hline$\square$ P3 & 421 & 6.2 & 3.2 & 0.421 & 15,292 & 32,286 \\
\hline
\end{tabular}

FIGURE 1: Flow cytometric analytical gating strategy. Tregs were evaluated, after selecting on gated CD45 ${ }^{+}$lymphocytes (P1), CD4 ${ }^{+}$cells $(\mathrm{P} 2)$ as cells with $\mathrm{CD} 25^{+}$at high density and CD127 low density or undetectable levels (P3). 


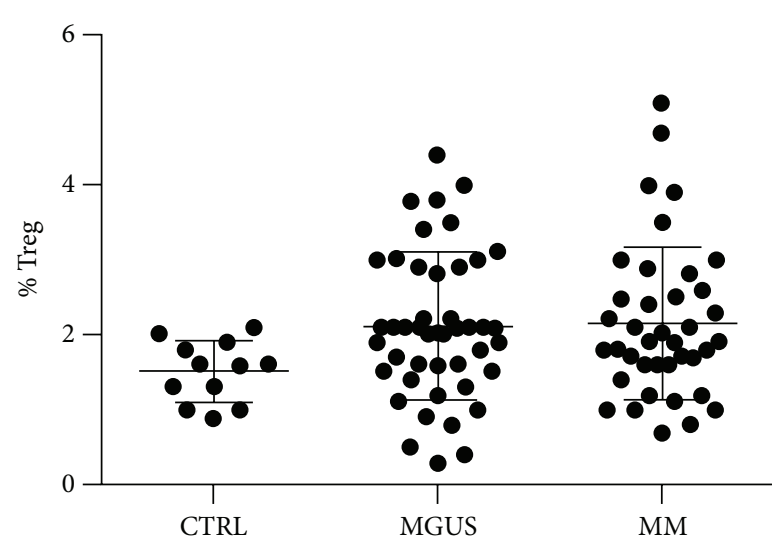

(a)

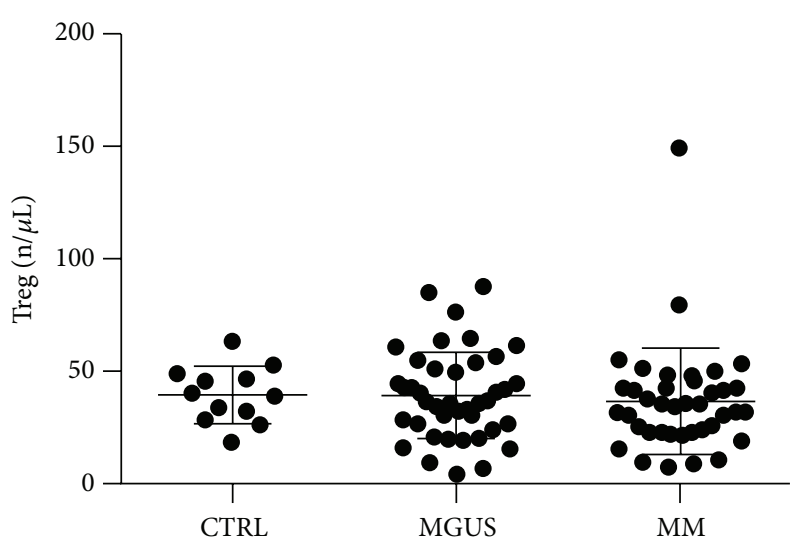

(b)

Figure 2: Circulating Tregs, detected as percentage of all lymphocytes (a) and as absolute number (b) in controls (CTRL), monoclonal gammopathy of uncertain significance (MGUS), and multiple myeloma (MM) patients, including those with smoldering MM (SMM). Horizontal bars indicate mean ( \pm standard deviation) values. No statistically significant differences were found among the three groups.

between two variables was measured using Spearman rank correlation for nonparametric data to assure the pertinence of all variables. Progression-free survival (PFS) was measured from time of diagnosis to time of progression into overt MM for MGUS and SMM or after an effective first-line therapy in MM patients; overall survival (OS) was determined from time of diagnosis to death event. The Kaplan-Meier method was used to analyze both PFS and OS. The receiver-operatorcurve (ROC) analysis was performed to estimate cut-off of Tregs (as number or percentage) to predict progression or survival. Statistical significance was defined as $p<0.05$. Statistical analyses were performed using $\mathrm{R}$ statistical software (version 3.2.0; R Foundation for Statistical Computing).

\section{Results}

Overall, the mean number of circulating Tregs, detected as percentage of all lymphocytes, was $2.1 \% \pm 1.0$ (range $0.75-$ $6.1 \%$ ) in MM patients; $2.1 \% \pm 0.9$ (range $0.3-4.4 \%$ ) in MGUS; and $1.5 \% \pm 0.4$ (range $0.9-2.1 \%$ ) in controls ( $p$ ns) (Figure 2). Mean absolute number of Tregs was $36.3 / \mu \mathrm{L} \pm 23.7$ (range $6.7-149 / \mu \mathrm{L}$ ) in $\mathrm{MM} ; 38.8 / \mu \mathrm{L} \pm 19.1$ (range $4.3-87 / \mu \mathrm{L}$ ) in MGUS; and $39.4 / \mu \mathrm{L} \pm 12.5$ (range $18-63 / \mu \mathrm{L}$ ) in controls $(p$ ns) (Figure 2). Patients with SMM were included within the MM group because of their mean percentage and absolute number levels for Tregs did not significantly differ from those of MGUS and active MM patients (data not shown).

After a median follow-up of 38 months (range 28-42 months) 5 MGUS and 2 SMM transformed into overt MM; however both percentage and absolute number of Tregs did not predict this evolution. Moreover, with respect to MM patients and after a median follow-up of 33 months (range 22-40 months), Tregs did not show any significant correlation with main clinical and laboratory characteristics, in particular with the type and amount of M-component, international staging system (ISS), bone marrow plasma cell infiltration, PFS, and OS (data not shown). As cytogenetic

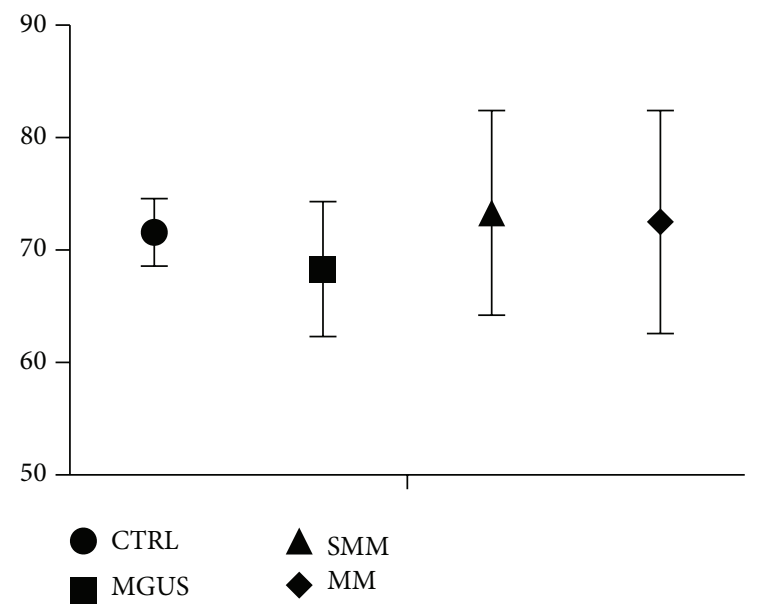

FIgure 3: Percentage of inhibition of autologous $\mathrm{CD} 4^{+} \mathrm{CD} 25^{-}$cells in healthy controls (CTRL) $(71.6 \% \pm 3 \%)$, monoclonal gammopathy of uncertain significance (MGUS) $(68.3 \% \pm 6 \%)$, smoldering multiple myeloma (SMM) $(73.3 \% \pm 9.1 \%)$, and active multiple myeloma (MM) $(72.5 \% \pm 9.9 \%)$ ( $p$ ns).

data were available only in a minority of MM patients, it was not possible to include this parameter in the analysis.

As shown in Figure 3, from a functional point of view, Tregs demonstrated to be able to inhibit autologous $\mathrm{CD} 4^{+} \mathrm{CD} 25^{-}$cells at a mean rate of $71.6 \% \pm 3 \%$ in healthy controls, $68.3 \% \pm 6 \%$ in MGUS, $73.3 \% \pm 9.1 \%$ in SMM, and $72.5 \% \pm 9.9 \%$ in active MM ( $p$ ns).

\section{Discussion}

Though it has been hypothesized that Tregs accumulate in the course of MM exerting an immunosuppressive function, thus favoring the progression of the disease, conflicting results have been published so far on the frequency and prognostic relevance of Tregs in monoclonal gammopathies (Table 2) 


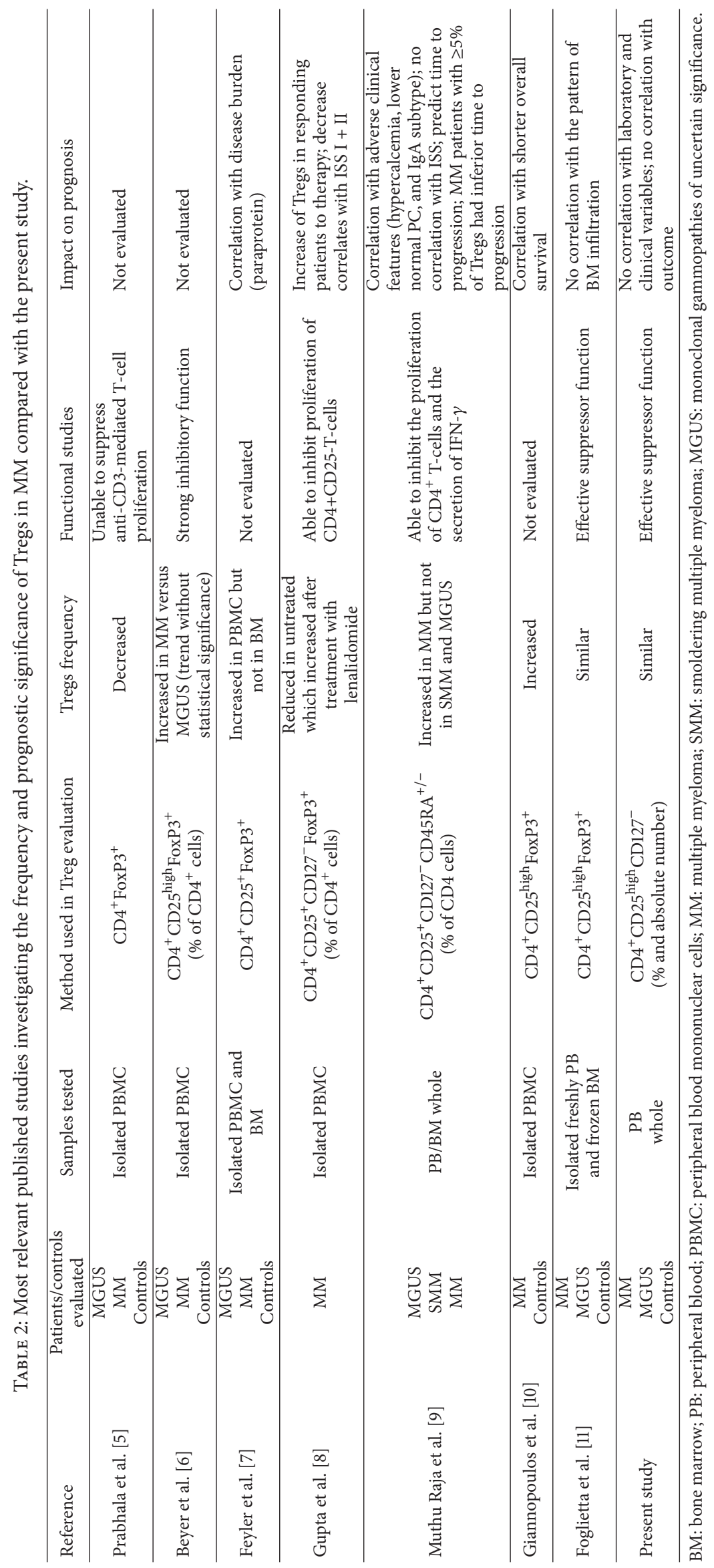


[5-11]. The variable results reported by different groups which have investigated Tregs in MM are at least in part probably due to the heterogeneous experimental approaches used: bone marrow, whole blood, isolated peripheral blood mononuclear cells (PBMC), depletion of $\mathrm{CD}_{2} 5^{+} \mathrm{T}$-cells, different panel of monoclonal antibodies, and different analytical strategy to identify Tregs by means of flow cytometry (Table 2). In this setting, we choose to use CD127 evaluation, instead of FoxP3, to avoid technical bias due to permeabilization techniques and the subjectivity related to the variable expression of CD25 [3]. Furthermore, in our study, we analyzed peripheral blood. This must be taken into account because bone marrow Tregs frequency may differ from that found in peripheral blood. In fact, it has been reported that MM microenvironment support overexpression of FOXP3 and CTLA4 expression in bone marrow, thus suggesting an accumulation of immunosuppressive Tregs in the tumor microenvironment of MM patients [14]. The tumor growth and the failure of local immune control may be favored by changes in the bone marrow microenvironment, such as the accumulation of Tregs that may contribute to the immune imbalance in MM. However, in some studies, frequencies and total counts of Tregs were found similar in the bone marrow and peripheral blood of MM patients and control subjects [11].

In almost all functional studies, Tregs activity was found comparable to that of healthy subjects, with the exception of the Prabhala et al. study [5]. In a critical revision published by Muthu Raja et al., this was attributed to the use of PBMC as responder cells [15]. From a functional point of view, our data are completely in agreement with those recently reported by Foglietta et al. [11].

Of interest, among their pleiotropic functions, immunomodulatory agents thalidomide and lenalidomide, currently used as standard therapy in MM, are able to decrease Tregs number and to inhibit their proliferation and immunosuppressive function $[16,17]$. Other studies, however, have instead suggested that Tregs number may be increased using these drugs $[17,18]$.

Finally, two groups recently found that symptomatic MM patients with long-term survival ( $>10$ years), accounting for about 5\% of all MM patients, displayed a distinct immunological profile characterized by a lower number of $\mathrm{BM}$ and circulating Tregs, higher Th17 cells, and proliferative cytotoxic T-cells, compared to patients with shorter survival $[19,20]$. Our study does not seem to support such an observation, but the relatively short follow-up of patients should be considered.

In conclusion, our results indicate that the circulating number of Tregs does not differ among MGUS, MM, and normal subjects and does not seem to influence disease status or to provide prognostic information in MM patients as well. However, due to the contrasting results published so far, further studies are needed to better understand the possible role of Tregs in the pathogenesis and disease progression of $\mathrm{MM}$, also in the light of the emerging role of novel immunotherapies, such as monoclonal antibodies, potentially active on minimal residual disease after specific treatments. Finally, the relevance of standardized methods to approach this field of investigation is also emphasized by the critical review of published data.

\section{Competing Interests}

The authors declare that they have no competing interests.

\section{References}

[1] G. D’Arena, S. Deaglio, L. Laurenti et al., "Targeting regulatory T cells for anticancer therapy," Mini-Reviews in Medicinal Chemistry, vol. 11, no. 6, pp. 480-485, 2011.

[2] S. Sakaguchi, N. Sakaguchi, J. Shimizu et al., "Immunologic tolerance maintained by $\mathrm{CD} 25^{+} \mathrm{CD} 4^{+}$regulatory $\mathrm{T}$ cells: their common role in controlling autoimmunity, tumor immunity, and transplantation tolerance," Immunological Reviews, vol. 182, pp. 18-32, 2001.

[3] B. Fazekas de St Groth, E. Zhu, S. Asad, and L. Lee, "Flow. Cytometric detection of human regulatory T cells," in Regulatory $T$ Cells: Methods and Protocols, Methods in Molecular Biology, G. Kassiotis and A. Liston, Eds., vol. 707, pp. 263-279, 2011.

[4] G. D'Arena, F. D’Auria, V. Simeon et al., "A shorter time to the first treatment may be predicted by the absolute number of regulatory T-cells in patients with Rai stage 0 chronic lymphocytic leukemia," American Journal of Hematology, vol. 87, no. 6, pp. 628-631, 2012.

[5] R. H. Prabhala, P. Neri, J. E. Bae et al., "Dysfunctional T regulatory cells in multiple myeloma," Blood, vol. 107, no. 1, pp. 301304, 2006.

[6] M. Beyer, M. Kochanek, T. Giese et al., "In vivo peripheral expansion of naive $\mathrm{CD} 4^{+} \mathrm{CD} 25^{\text {high }} \mathrm{FoxP}^{+}$regulatory T cells in patients with multiple myeloma," Blood, vol. 107, no. 10, pp. 3940-3949, 2006.

[7] S. Feyler, M. von Lilienfeld-Toal, S. Jarmin et al., " $\mathrm{CD} 4^{+} \mathrm{CD} 25^{+} \mathrm{FoxP}^{+}$regulatory $\mathrm{T}$ cells are increased whilst $\mathrm{CD}^{+}{ }^{+} \mathrm{CD} 4^{-} \mathrm{CD} 8-\alpha \beta \mathrm{TCR}^{+}$Double Negative $\mathrm{T}$ cells are decreased in the peripheral blood of patients with multiple myeloma which correlates with disease burden," British Journal of Haematology, vol. 144, no. 5, pp. 686-695, 2009.

[8] R. Gupta, P. Ganeshan, M. Hakim, R. Verma, A. Sharma, and L. Kumar, "Significantly reduced regulatory $\mathrm{T}$ cell population in patients with untreated multiple myeloma," Leukemia Research, vol. 35, no. 7, pp. 874-878, 2011.

[9] K. R. Muthu Raja, L. Rihova, L. Zahradova, M. Klincova, M. Penka, and R. Hajek, "Increased T regulatory cells are associated with adverse clinical features and predict progression in multiple myeloma," PLoS ONE, vol. 7, no. 10, Article ID e47077, 2012.

[10] K. Giannopoulos, W. Kaminska, I. Hus, and A. Dmoszynska, "The frequency of $\mathrm{T}$ regulatory cells modulates the survival of multiple myeloma patients: detailed characterisation of immune status in multiple myeloma," British Journal of Cancer, vol. 106, no. 3, pp. 546-552, 2012.

[11] M. Foglietta, B. Castella, S. Mariani et al., “The bone marrow of myeloma patients is steadily inhabited by a normal-sized pool of functional regulatory T cells irrespective of the disease status," Haematologica, vol. 99, no. 10, pp. 1605-1610, 2014.

[12] G. D’Arena, L. Laurenti, M. M. Minervini et al., "Regulatory T-cell number is increased in chronic lymphocytic leukemia patients and correlates with progressive disease," Leukemia Research, vol. 35, no. 3, pp. 363-368, 2011. 
[13] B. Castella, C. Riganti, F. Fiore et al., "Immune modulation by zoledronic acid in human myeloma: an advantageous cross-talk between $\mathrm{V} \gamma 9 \mathrm{~V} \delta 2 \mathrm{~T}$ cells, $\alpha \beta \mathrm{CD}^{+} \mathrm{T}$ cells, regulatory $\mathrm{T}$ cells, and dendritic cells," The Journal of Immunology, vol. 187, no. 4, pp. 1578-1590, 2011.

[14] W. M. T. Braga, B. R. da Silva, A. C. de Carvalho et al., "FOXP3 and CTLA4 overexpression in multiple bone marrow as a sign of accumulation of $\mathrm{CD} 4^{+} \mathrm{T}$ regulatory cells," Cancer Immunology, Immunotherapy, vol. 63, no. 11, pp. 1189-1197, 2014.

[15] K. R. Muthu Raja, Kovářová L, J. Štossová, and R. Hájek, "Flow cytometric phenotyping and analysis of $\mathrm{T}$ regulatory cells in multiple myeloma patients," Klinicka Onkologie, vol. 24, supplement, pp. S30-S33, 2011.

[16] C. S. Kasyapa, T. Sher, and A. A. Chanan-Khan, "Multiple myeloma and immunomodulation: regulating the regulatory cells," Leukemia and Lymphoma, vol. 53, no. 7, pp. 1253-1254, 2012.

[17] C. Galustian, B. Meyer, M.-C. Labarthe et al., "The anti-cancer agents lenalidomide and pomalidomide inhibit the proliferation and function of T regulatory cells," Cancer Immunology, Immunotherapy, vol. 58, no. 7, pp. 1033-1045, 2009.

[18] K. R. Muthu Raja, L. Kovarova, and R. Hajek, "Induction by lenalidomide and dexamethasone combination increases regulatory cells of patients with previously untreated multiple myeloma," Leukemia and Lymphoma, vol. 53, no. 7, pp. 14061408, 2012.

[19] C. Bryant, H. Suen, R. Brown et al., "Long-term survival in multiple myeloma is associated with a distinct immunological profile, which includes proliferative cytotoxic T-cell clones and a favourable Treg/Th17 balance," Blood Cancer Journal, vol. 3, no. 9, article el48, 2013.

[20] R. J. P. de Magalhães, M.-B. Vidriales, B. Paiva et al., "Analysis of the immune system of multiple myeloma patients achieving long-term disease control by multidimensional flow cytometry," Haematologica, vol. 98, no. 1, pp. 79-86, 2013. 


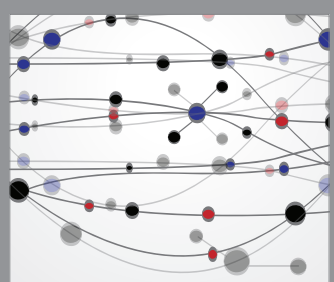

The Scientific World Journal
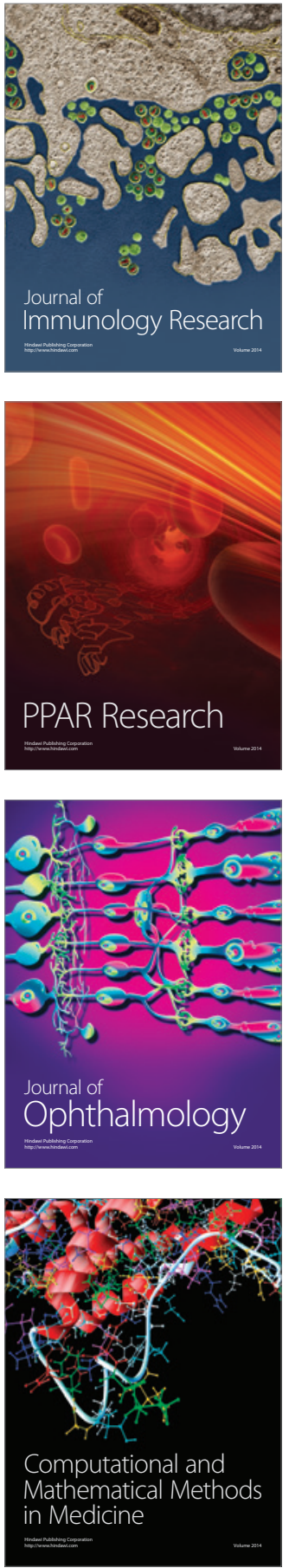

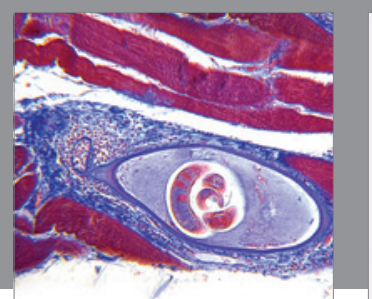

Gastroenterology Research and Practice

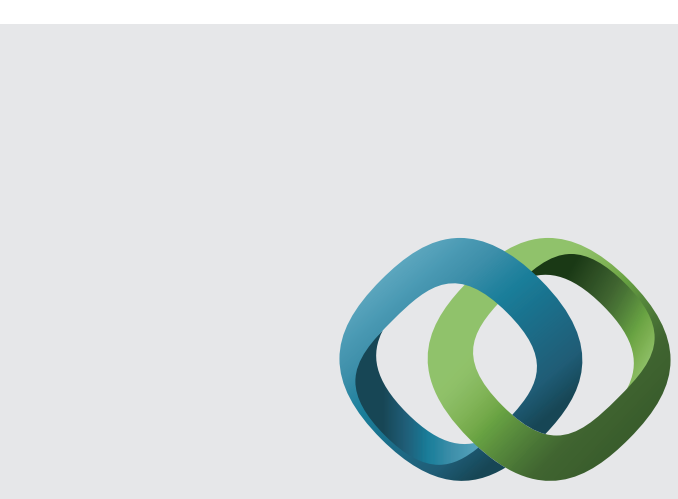

\section{Hindawi}

Submit your manuscripts at

http://www.hindawi.com
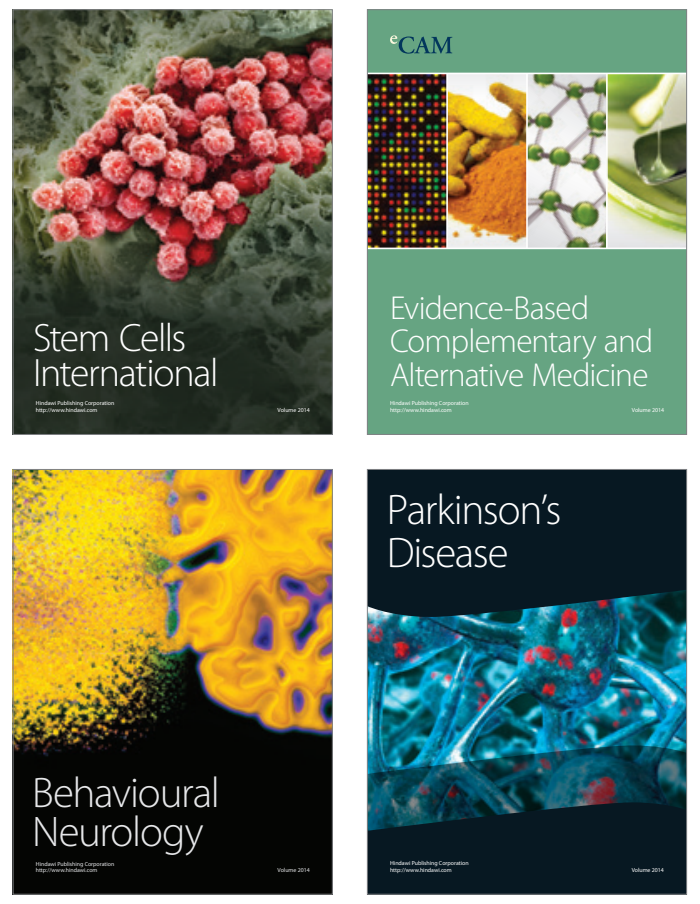
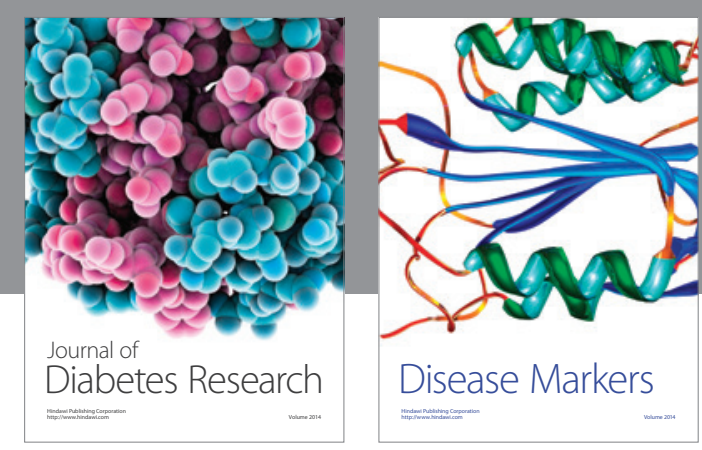

Disease Markers
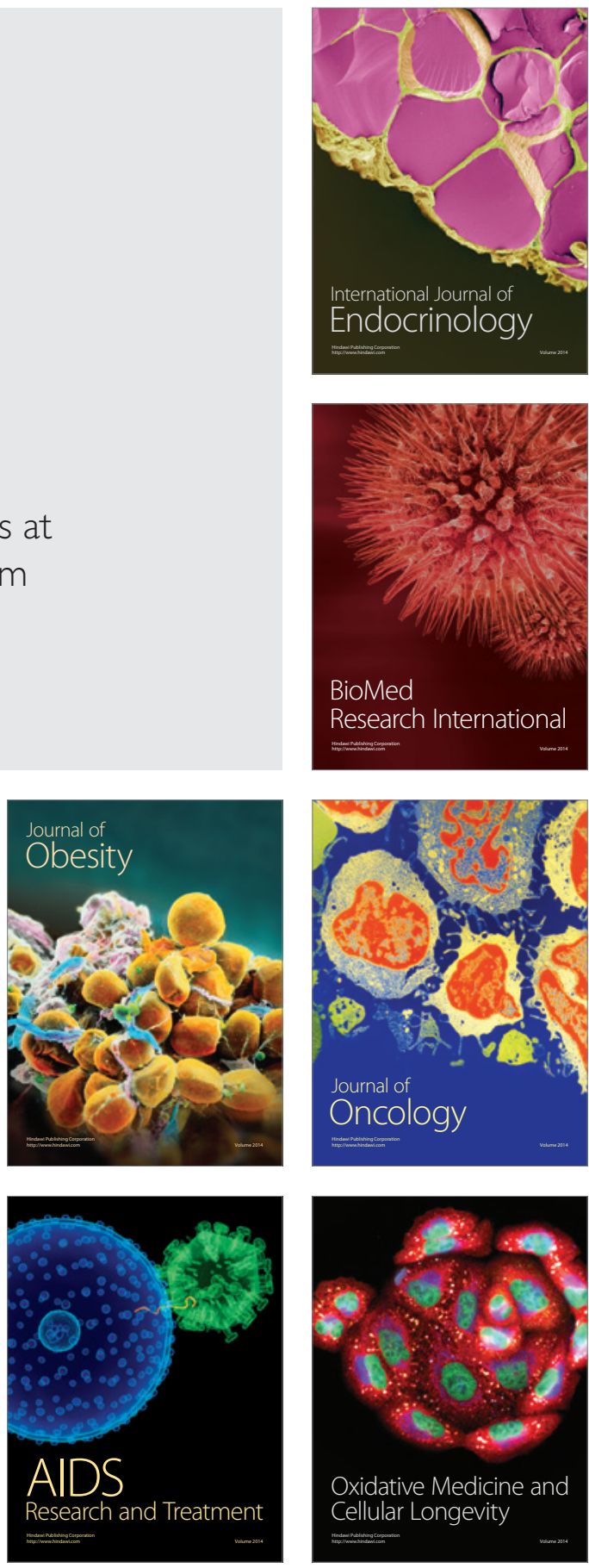